\title{
Editorial
}

\section{Beyond Techno-Utopia: Critical Approaches to Digital Health Technologies}

\section{Deborah Lupton}

News and Media Research Centre, Faculty of Arts and Design, University of Canberra, Building 9, Bruce ACT 2601, Australia; E-Mail: deborah.lupton@canberra.edu.au; Tel.: +61-(0)-2-6295-0076

External Editor: Jacqueline Low

Received: 26 November 2014 / Accepted: 4 December 2014 / Published: 8 December 2014

\begin{abstract}
This editorial presents an overview of digital health technologies, discusses previous research and introduces the contributions to the special issue "Beyond Techno-Utopia: Critical Approaches to Digital Health Technologies”. It is argued that thus far, few critical analyses of digital health technologies have been published in the social science literature, particularly in relation to the newest technologies. While the articles collected here in this special issue have gone some way in offering a critical response to digital health technologies, they represent only a beginning. Many more compelling topics remain to be investigated. The editorial ends with outlining directions for future research in this area.
\end{abstract}

Keywords: digital health; critical perspectives; social sciences

The title for this special issue was devised as a direct challenge to the prevailing solutionist and instrumental approaches to the application of digital technologies to medicine and public health. In formulating the idea and title for the special issue, I wanted to inspire some provocative and challenging commentary and research to what I interpreted as a dominantly techno-utopian position on digital health. One important approach that I particularly wanted to encourage, and which I articulate in my own contribution to the special issue, is that which views digital health technologies as social, cultural and material artefacts which have political implications and embodied entanglements with humans and other nonhuman actors.

Three waves of digital technology adoption have been identified in healthcare. The first wave began in the 1950s, when nascent computerised technologies were used to automate standardised and repetitive tasks such as accounting and payroll-related data entry. Health insurance companies and other industry stakeholders also used computers to analyse data. The second wave of digital 
technology use in healthcare emerged in the 1970s, incorporating the development of health informatics and electronic health card systems. Both waves incorporated individual institutions establishing systems for more efficient data management and processing. The third wave is emerging in the current era. This wave sees moves towards the digitisation of as many elements of healthcare as possible and the interaction and exchange of data between different institutions and systems: an overarching framework that incorporates data not only from healthcare institutions and systems but actors and agencies outside this sector [1].

Over the past few years, an emerging discourse on digital health technologies (also referred to as mHealth, eHealth, connected health and Health 2.0) has represented them as offering unprecedented solutions to the "wicked problems" of medicine and public health. In popular forums, among digital developers and entrepreneurs and in the medical and public health literature a constant refrain has insisted on the "disruptive" and "revolutionary" nature of these technologies and their potential to address budgetary constraints and healthcare delivery limitations and to facilitate health promotion, preventive medicine and public health surveillance. Digital health technologies encompass a wide range of devices and software. These include the use of social media by both members of the lay public and healthcare or public health professionals to discuss health and medical issues and disseminate information; remote healthcare consultations and patient self-care using digital technologies (telemedicine and telehealth); the use of virtual reality in medical training; the rapidly expanding number of mobile applications ("apps") devoted to health and medical matters (now numbering in the tens of thousands); health informatics systems in healthcare delivery; public health surveillance using big data to track disease patterns; wearable self-tracking devices and gaming technologies for monitoring bodily functions and activities using sensors; health promotion employing social media and text messages; 3D printing of medical devices and prosthetics; and community development and activist initiatives involving citizen science/citizen sensor activities to generate environmental information on their local area (see overviews in [2,3]).

Digital health technologies and the medical gaze extend well beyond the clinic. They now penetrate into many social domains and intersect with a multitude of objectives and purposes. It is clear that health monitoring technologies and the personal data that they generate are viewed as significant commercial opportunities for digital developers. Major companies such as Apple, Samsung, Microsoft and Google are now entering the digital health arena: all four announced their plans to launch health and fitness tracking platforms in 2014. Healthcare, pharmaceutical and biotechnology companies are using social and other digital media for marketing and public relations purposes. This takes place in a variety of ways, from the traditional explicit type of marketing such as sponsoring banner ads and conferences, to the covert, such as attempting to influence social media discussions on platforms such as Facebook or Twitter. The collection of personal data by self-tracking devices has been taken up and repurposed by employers, educational institutions, health and life insurance and customer loyalty programs [4]. These technologies bring voluntary individual health-related behaviours (such as a lay person choosing to download a health-related app) or communal sharing of experiences (as in patient support platforms such as PatientsLikeMe) together with the imposed or "pushed" use of devices (for instance patients being sent home from hospital with wireless self-monitoring technologies) and the use of people's personal digital data by actors and agencies for their own managerial or commercial 
purposes, often without their knowledge or consent (for example the "harvesting” of social media content by biopharmaceutical companies) [4].

While there is an extensive literature on older forms of digital technologies that have been used for health and medical purposes (such as blogs, websites and telemedicine), academic researchers, particularly in the social sciences, have yet to devote much attention to the newer technologies that have emerged over the past half-decade or so: apps, wearable and citizen sensing devices and 3D printing, for example. Most of the publications that have appeared on these topics have been published in the medical and public health literature. The writers take a largely instrumental approach that is interested in the efficacy of digital technologies or professional issues such as accuracy of the information provided or conflict of interest concerns. For example a recent meta-analysis of the literature that has been published investigating social media use in medicine and healthcare found evidence of the growing use of social media in these sectors. The authors identified across these publications recurrent themes related to ethics, professionalism, privacy, confidentiality and information quality [5].

The available information on the usage statistics of digital technologies mostly comes from market research, although the Pew Internet Center has also conducted valuable surveys on the American population. A 2013 Pew report noted that 59 per cent of American adults said that they had searched online for health-related information, with over one-third of their respondents reporting using the internet to self-diagnose or diagnose someone else's condition [6]. Recent market research surveys have found that more than a third of American doctors had recommended that their patients use a health or medical app and that almost one-third of American smartphone owners had used health and fitness apps [7]. However while a great deal of hype and excitement have been expressed about the possibilities and potential of digital health in entrepreneurial digital developer circles and news reports, the reality of use does not always reach expectations. For example other market research has found that while in 2013 one in ten American adults owned a digital fitness tracker, a high proportion of people (more than half) had relinquished their use; one third had given up using it within six months of purchase [8].

The articles in this special issue build on a well-established literature in sociology, science and technology studies and media and cultural studies that has addressed the use of digital technologies in health and medicine. This research has particularly focused on patients' and healthcare professionals' experiences of telemedicine and telehealth, lay people's use of websites and social media for seeking information about health and medical topics and sharing experiences of specific conditions, the inequalities that are evident in different social groups' use of digital technologies for health- and medical-related purposes and the sociocultural dimensions of the digitising of human bodies (see [2] for a review of this literature). Studies on patients' experiences of using digital technologies for at-home self-care, for example, have demonstrated the complexities, ambivalences and strong emotions that are involved. Patients may find using these devices empowering, allowing them to reduce travel to see their healthcare provider or to live independently at home. However, many patients resent the incursion into their homes of medical devices that constantly remind them that they are old and infirm or are dealing with a serious chronic illness, or make them feel that they are under constant surveillance. Furthermore, while the devices promise certainty and simplicity, they are often difficult to use and ambiguous in the information they convey [9-13]. 
Several of these topics are taken up in the articles published in this special issue. All the authors use social and cultural theory to provide insights into the tacit assumptions, cultural meanings and experiences of digital health technologies. The articles cover a range of digital health technologies: devices used for the self-tracking of body metrics (Ruckenstein; Till; Rich and Miah; Lupton); social media platforms for discussing patients' experiences of chronic disease (Sosnowy) and experiences of pregnancy and early motherhood (Johnson); health and medical apps (Till; Johnson; Christie and Verran; Lupton); telehealthcare systems (Hendy, Chrysanthaki and Barlow); and a digital public health surveillance system (Cakici and Sanches). While some articles focus on globalised digital media (Cakici and Sanches; Rich and Miah; Till; Lupton), others engage more specifically with a range of sociocultural groups, contexts and locations. These include Aboriginal people living in a remote region of Australia (Christie and Verran) and Australian mothers in urban Sydney (Johnson) as well as research participants in Helsinki, Finland (Ruckenstein), the United States (Sosnowy) and England (Hendy, Chrysanthaki and Barlow).

Understandings and experiences of selfhood and embodiment as they are generated and experienced via digital health devices are central preoccupations in the articles by Ruckenstein, Rich and Miah, Till, Lupton, Sosnowy and Johnson. Ruckenstein's study of self-trackers found that they often conceptualised their bodies and their physical activities in different ways when these were being monitored and rendered into digital data. The data that were generated by these devices proved to be motivational and to give value to some activities (like housework) that otherwise lacked value or new meaning to functions such as sleep (which when digitised and quantified became viewed as a competence). Ruckenstein found that the digital data tended to be invested with greater validity than were other indicators of bodily wellbeing or activity, such as the individual's physical sensations.

All of the above authors comment on the ways in which digital health devices such as wearable self-tracking devices, social media platforms, apps and patient support websites work as disciplinary tools. They invite users to conform to the ideals of healthism (privileging good health above other priorities) and the responsible self-management and self-monitoring of one's health and body, including avoiding exposure to risk. Rich and Miah use the concept of "public pedagogy" to describe the socio-political dimensions of digital health technologies as they are employed to educate people about their bodies and promote self-management. As Johnson notes, for women who are pregnant or have the care of young children, this sphere of responsibility is extended to the bodies of others: the foetus or child. And as Till's article emphasises, when employees are "encouraged" to engage in self-tracking, the ethos of responsibility extends from personal objectives to those of employers.

Ruckenstein, Till and Sosnowy also highlight the digital labour involved for people who engage with social media or self-tracking apps as part of their personal health or fitness practices. Sosnowy's interviews with women with multiple sclerosis who blog about their condition emphasise the work involved in such engagement as an "active patient”. Till's analysis of digital exercise self-tracking points to the appropriations of people's labour by other actors for commercial reasons.

The article by Hendy, Chrysanthaki and Barlow moves in a somewhat different direction. Using ethnographic cases studies, they look at the managerial issues involved with implementing telehealthcare in English social and health care organisations. Their focus, therefore, is not on the recipients or targets of digital health technologies but rather those who are attempting to institute programs as part of their work as managers. These authors' contribution highlights the messiness of 
introducing new systems and practices into large organisations, and the resistances that may emerge on the part of both workers and the targets of telehealthcare programs. Cakici and Sanches' article also takes an organisational perspective in addressing a European Commission co-funded project directed at syndromic surveillance, or the use of secondary sources to detect outbreaks and patterns in diseases and medical conditions. Digital data are increasingly being use as part of syndromic surveillance: Google Flu Trends is one such example. Cakici and Sanches' analysis highlights the role played by human decision-making and the affordances of digital technologies in structuring what kinds of data are retrieved for syndromic surveillance and how they are interpreted.

While there are as yet few detailed ethnographic accounts of how people are implementing, adopting or resisting contemporary digital health technologies, there are even fewer that investigate the use of these technologies by members of cultural groups outside the global North. The article by Christie and Verran takes a much-needed diversion from perspectives on white, privileged groups to Aboriginal people living in a remote part of Australia. As they argue, the concepts on health, illness and the body that are held by this cultural group differ radically from the tacit assumptions that are invested in mainstream health and medical apps. Any app that is developed to assist in health literacy that is targeted at this group must incorporate culturally-appropriate modes of communication: positioning people within their cultural and kinship networks of sociality, for example, rather than representing them as atomised actors.

The articles collected here in this special issue have gone some way in offering a critical response to digital health technologies, but they represent only a beginning. Many more compelling topics remain to be investigated. These include research into the ways in which lay people and healthcare professionals are using (or resisting the use) of social media, apps and self-monitoring devices for medicine and health-related purposes; the implications for medical power and the doctor-patient relationship; how citizen science and citizen sensing are operating in the public health domain; the development of new digital health technologies; the implications of big data and data harvesting in medicine and healthcare; the spreading out of health-related self-tracking practices into many social domains; the unintended consequences and ethical aspects of digital technology use and their implications for social justice; and data security and privacy issues.

\section{Conflicts of Interest}

The author declares no conflict of interest.

\section{References}

1. Biesdorf, S.; Niedermann, F. Healthcare’s digital future. McKinsey \& Company, July 2014. Available online: http://www.mckinsey.com/insights/health_systems_and_services/healthcares_digital_future (accessed on 5 August 2014).

2. Lupton, D. Critical perspectives on digital health technologies. Sociol. Compass 2014, in press.

3. Lupton, D. Health promotion in the digital era: A critical commentary. Health Promot. Int. 2014, doi:10.1093/heapro/dau091.

4. Lupton, D. Self-tracking modes: Reflexive self-monitoring and data practices. Available online: http://ssrn.com/abstract=2483549 (accessed on 28 November 2014). 
5. Grajales, J.F.; Sheps, S.; Ho, K.; Novak-Lauscher, H.; Eysenbach, G. Social media: A review and tutorial of applications in medicine and health care. J. Med. Internet Res. 2014, 16, e13. Available online: http://www.jmir.org/204/2/e13/ (accessed on 25 November 2014).

6. Fox, S.; Duggan, M. Health online. Available online: http://www.pewinternet.org/2013/01/15/healthonline-2013/ (accessed on 14 February 2014).

7. MobiHealthNews. In-depth: Q2 2014 digital health state of the industry. Available online: http://mobihealthnews.com/36044/in-depth-q2-2014-digital-health-state-of-the-industry/ (accessed on 25 August 2014).

8. Ledger, D.; McCaffrey, D. Inside Wearables: How the Science of Human Behavior Change Offers the Secret to Long-Term Engagement; Endeavour Partners: Cambridge, MA, USA, 2014.

9. Greenhalgh, T.; Wherton, J.; Sugarhood, P.; Hinder, S.; Procter, R.; Stones, R. What matters to older people with assisted living needs? A phenomenological analysis of the use and non-use of telehealth and telecare. Soc. Sci. Med. 2013, 93, 86-94.

10. Pols, J. Care at a Distance: On the Closeness of Technology; Amersterdam University Press: Amsterdam, The Netherlands, 2012.

11. Mol, A.; Law, J. Embodied action, enacted bodies: The example of hypoglycaemia. Body Soc. 2004, 10, 43-62.

12. Mol, A. Living with diabetes: Care beyond choice and control. Lancet 2009, 373, 1756-1757.

13. Oudshoorn, N. Telecare Technologies and the Transformation of Healthcare; Palgrave Macmillan: Houndmills, UK, 2011.

(C) 2014 by the author; licensee MDPI, Basel, Switzerland. This article is an open access article distributed under the terms and conditions of the Creative Commons Attribution license (http://creativecommons.org/licenses/by/4.0/). 